\section{Quantitative evaluation of CART-containing cells in urinary bladder of rats with renovascular hypertension}

\author{
I. Janiuk, ${ }^{1}$ I. Kasacka² \\ 'Department of Dietetics and Food \\ Assessment, Institute of Health Sciences, \\ University of Natural Sciences and \\ Humanities, Siedlce \\ 2Department of Histology and \\ Cytophysiology, Faculty of Pharmacy, \\ Medical University of Bialystok, Poland
}

transitional epithelium cells.

As this study provides novel findings, the question appears about the type of connection between hypertension and the functioning and activity of CART in the urinary tract (UT). The study gives rise to the assumption that high blood pressure can be a factor that intensifies CART secretion. In conclusion, the endocrine system of the urinary tract is modified by renovascular hypertension. This may affect the production of hormones and biologically active substances and contribute to the development of possible hypertension complications. In order to fully comprehend the role of the CART peptide in blood pressure regulation, further analyses are necessary.

\section{Abstract}

Recent biological advances make it possible to discover new peptides associated with hypertension. The cocaine- and amphetamineregulated transcript (CART) is a known factor in appetite and feeding behaviour. Various lines of evidence suggest that this peptide participates not only in control of feeding behaviour but also in the regulation of the cardiovascular and sympathetic systems and blood pressure. The role of CART in blood pressure regulation led us to undertake a study aimed at analysing quantitative changes in CART-containing cells in urinary bladders (UB) of rats with renovascular hypertension. We used the Goldblatt model of arterial hypertension (twokidney, one clip) to evaluate quantitative changes. This model provides researchers with a commonly used tool to analyse the reninangiotensin system of blood pressure control and, eventually, to develop drugs for the treatment of chronic hypertension. The study was performed on sections of urinary bladders of rats after 3-, 14-, 28-, 42 and 91 days from hypertension induction. Immunohistochemical identification of CART cells was performed on paraffin for the UBs of all the study animals. CART was detected in the endocrine cells, especially numerous in the submucosa and muscularis layers, with a few found in the transitional epithelium and only occasionally in serosa. Hypertension significantly increased the number of CART-positive cells in the rat UBs. After 3 and 42 days following the procedure, statistically significantly higher numbers of CART-positive cells were identified in comparison with the control animals. The differences between the hypertensive rats and the control animals concerned not only the number density of CART-immunoreactive cells but also their localization. After a 6 -week period, each of the rats subjected to the renal artery clipping procedure developed stable hypertension. CART appeared in numerous

\section{Introduction}

Renovascular hypertension is a common disorder and an illness with an added social dimension. ${ }^{1}$ It sporadically occurs as an isolated condition, however more often it occurs in combination with other illnesses, especially metabolic disorders, including disorders of lipid and lipoprotein management, diabetes, obesity, hyperuricemia and changes in the quantitative composition of clotting factors. There are genetic predispositions and disorders of complex mechanisms regulating blood pressure underlying both primary and secondary hypertension. It is postulated that the nervous and endocrine systems, kidneys and local factors regulating the tension of muscles in blood vessels are responsible for regulating the pressure. ${ }^{2}$ The results of research in recent years also suggest a considerable role of the endocrine system, including various types of highly specialized, diffusively located receptoreffector cells included in the diffuse neuroendocrine system (DNES). These cells produce active substances that affect the coordination of a wide range of functions of organs and are direct regulators of homeostasis in the body. However, they can simultaneously play roles as mediators in several circulatory disorders, including renovascular hypertension. ${ }^{3}$ Among the active substances secreted by DNES cells, there is the cocaine and amphetamine regulated transcript (CART), produced and secreted in the hypothalamus and in other tissues in many vertebrates. ${ }^{4-11}$ Despite considerable progress made in the area of structure and physiological description of this factor, its role in the pathogenesis of human hypertension is controversial. The development of techniques in molecular biology and histochemistry has enabled research on the distribution and precise tissue localization of the CART peptide in many organs. The principal site of CART synthesis is in areas of the brain, involved in the
Correspondence: Dr. Izabela Janiuk, Department of Dietetics and Food Assessment, Institute of Health Sciences, Siedlce University of Natural Sciences and Humanities, Prusa 14 Street, 08110 Siedlce, Poland.

Tel. +48.25.6431284 - Fax: +48.25.6431353.

E-mail: izabela.janiuk@uph.edu.pl

Keywords: CART, urinary bladder, renovascular hypertension, rat.

Funding: this work was supported by statutory funds from the University of Natural Sciences and Humanities of Siedlce, no. S/341/13.

Conflict of interest: the authors declare no conflict of interest.

Contributions: IK, study concept and design; IJ, $\mathrm{IK}$, data collection, analysis and interpretation of data; IJ, manuscript drafting;

Received for publication: 19 August 2014. Accepted for publication: 24 February 2015.

This work is licensed under a Creative Commons Attribution NonCommercial 3.0 License (CC BYNC 3.0).

CC Copyright I. Janiuk and I. Kasacka, 2015

Licensee PAGEPress, Italy

European Journal of Histochemistry 2015; 59:2446 doi:10.4081/ejh.2015.2446

control of blood pressure. ${ }^{9-11}$

CART is mainly known for its role in feeding anomalies, which result in hypophagia. This concerns a wide range of biological activities. Among others, CART has neurodegenerative properties after a stroke and is related to blood circulation and renovascular hypertension. . $^{10,12-14}$ Central administration of CART peptide increases systemic blood pressure ${ }^{15}$ and blocks phenylephrine-induced bradycardia. ${ }^{16}$ There is only limited information concerning the influence of CART on heart rate, blood pressure, stress and secretion of adrenal hormones. There is both anatomical and physiological evidence available that CART is engaged in hypothalamus - pituitary gland - adrenal gland (HPA) regulation. The HP axis represents one of the main limbs of an adaptive system, which maintains the basal and stress-related homeostasis in vertebrates. ${ }^{17}$ It is the main component of the neuroendocrine system responsible for the coordination of many systems, including the cardiovascular system..$^{17,18}$ The fact that CART is found at the level of, HPA as well as coexisting with peptides with pressor properties such as leptin, neuropeptide $\mathrm{Y}$ (NPY) or calcitonin gene related peptide (CGRP) ${ }^{17}$ can indicate a potential role of CART in physiological regulation of blood pressure. The presence of CART in the HPA axis is strict- 
ly related to activation of the sympathetic nervous system, leading to increased secretion of adrenaline and noradrenaline, which further starts a cascade of reactions from the cardiovascular system. In experimental research, the hypertensive activity of CART was verified by an intravenous injection and direct infusion into cerebral ventricles. Direct introduction of the peptide into the ventricles resulted in a reaction of the central nervous system (CNS), while no reaction was observed after the intravenous injection. A hypertensive effect was induced by intracerebral application of CART, which activated the sympathetic nervous system and caused an increase in mean arterial pressure and plasma glucose levels. ${ }^{10}$

To date, CART distribution has been identified in the urinary system, in the bladder of normotensive animals ${ }^{7}$ and in both the bladder and ureters of hypertensive animals after 42 days following the clamping of the left renal artery. ${ }^{6}$ The scarce information on the influence of the duration of hypertension on the endocrine system of the lower urinary tract prompted us to investigate the dynamics of changes in the number of NE cells secreting CART in the urinary bladder of rats with experimentally induced renovascular hypertension [Goldblatt's model of hypertension - two-kidney, one clip model (2K1C) ] ${ }^{19}$.

\section{Materials and Methods}

\section{Animal protocols}

The study included 6-week-old young male Wistar rats (Rattus norvegicus). Their body weight at the beginning of the experiment was 160 -180 g (mean body weight: $170 \pm 10 \mathrm{~g}$ ). The animals were maintained at $22 \pm 1^{\circ} \mathrm{C}$ with an alternating 12:12-hour light-darkness cycle. Food and water were available ad libitum. Animal protocols were reviewed and approved by the Senate Committee for Oversight of Experiments on Humans and Animals, Medical University in Bialystok, Poland (Resolution no. 49/2009 on 30.09.2009, concerning application no. 2009/45).

The animals were divided into 3 groups; the first group ( $\mathrm{n}=15)$ included sham- operated (S0) rats, the second group $(n=15)$ included control rats not undergoing any surgical procedures, and the third group $(\mathrm{n}=40)$ included rats with experimentally induced renovascular hypertension (2K1C). All procedures and measurements were performed at the same time of the day. After a 7-day acclimatization period, each rat had its systolic blood pressure (SBP) measured by the tail-cuff method ${ }^{20}$ and the arterial pressure was evaluated by using a Student Oscillograph Rat Tail Blood Pressure Monitor Kit (Harvard Apparatus, Holliston, MA, USA).

\section{Description of the experiment}

Induction of experimental hypertension was performed according to procedure developed by Goldblatt et al. ${ }^{19}$ After the rats were anaesthetised by exposure to pentobarbital (40 $\mathrm{mg} / \mathrm{kg}$, i.p.), a 3 -cm retroperitoneal flank incision was performed in sterile conditions. The left kidney was exposed and the renal artery was carefully dissected free of the renal vein. The renal artery was then partially occluded by placing a standardized silver clamp with an internal diameter of $0.22 \mathrm{~mm}$ on the vessel. The wound was closed with a running 3-0 silk suture. The sham-operated rats $(\mathrm{n}=15)$ underwent identical surgical procedures, except that a clip was not applied to the renal artery. After the surgery, the rats were kept in separate cages.

After 3, 14, 28, 42 and 91 days from the renal artery clipping procedure, all rats were weighed and the systolic arterial pressure was measured by the tail-cuff method. ${ }^{20}$ After this time, all the $2 \mathrm{~K} 1 \mathrm{C}$ rats $(\mathrm{n}=40)$ developed stable hypertension (mean blood pressure values $162.6 \pm 3.2 \mathrm{mmHg}$ ).

\section{Histology procedure}

After 3, 14, 28, 42 and 91 days following the clamping procedure and induction of renovascular hypertension, all the animals were put into a state of deep anesthesia with pentobarbital $(50 \mathrm{mg} / \mathrm{kg}$ body weight). After cardiac arrest, fragments of the bladder wall were collected from the animals, always from the same place (body of urinary bladder). Sections of the wall, sampled in the same way as from the experimental group, were collected from rats not undergoing any procedures to provide comparative material.

Tissues were fixed (72 $\mathrm{h}$ at room temperature) by immersion in $4 \%$ buffered formaldehyde and, following dehydration, were embedded in paraffin wax. The sections were cut 4 $\mu \mathrm{m}$ thick and attached to FLEX IHC microscope slides (K8020, Dako, Glostrup, Denmark).

\section{Immunohistochemical protocol}

The identification and visualization of CART in neuroendocrine cells (NE) was performed based on the EnVision method according to Herman and Elfont ${ }^{21}$ using a commercial polyclonal antibody against CART. For antigen retrieval, immunostaining was performed using the below protocol. The sections were deparaffinized in xylene and hydrated in a series of alcohols with decreasing concentration. The sections were subjected to pre-treatment in a pressure chamber heated for $1 \mathrm{~min}$ at 21 psi at $125^{\circ} \mathrm{C}$, using Target Retrieval Solution, pH of 9.0 (S 2367, Dako). After being cooled to room temperature, these sections were incubated with Peroxidase Blocking Reagent (S 2001, Dako) for 10 min to block endogenous activity. The sections with the primary antibody for the CART peptide (rabbit polyclonal CART antiserum, No H-003-61, purchased at the Phoenix Pharmaceuticals, Inc. Mountain View, CA, USA) were diluted (1:10,000) in antibody diluents (S 0809, Dako). The slides were incubated overnight at $4^{\circ} \mathrm{C}$ in a humidified chamber with the diluted antibody, followed by incubation with a secondary rabbit antibody (conjugated to horseradish peroxidase-labeled polymer) (EnVision+ Kit HRP Rabbit K4011, Dako) for 1 h. The bound antibodies were visualized by 1-min incubation using the 3,3'-diaminobenzidine (DAB) substrate chromogen. All of the sections were finally stained with Vector QS hematoxylin $(\mathrm{H}-$ 3404; Vector Laboratories, Inc., Burlingame, CA, USA), mounted and evaluated under a light microscope. Appropriate washing with Wash Buffer (S 3006, Dako) was performed between each step.

The specificity test performed for the CART antibody included: negative control, where the antibodies were replaced by normal rabbit serum (Vector Laboratories; Burlingame, CA, USA) at the respective dilution. Additionally, positive control was carried out for the specific tissue, as recommended by the producer (for our research we used rat hypothalamus). The stained preparations were analyzed under an Olympus BX 41 microscope. Two sections of each fragment of the urinary bladder from each animal were studied. The cells containing CART were localized and observed in 5 randomly selected fields of vision $\left(0.785 \mathrm{~mm}^{2}\right)$ at a $200 \times$ zoom ( $20 \times$ objective and $10 \times$ eyepiece) of the analyzed urinary bladder section area.

\section{Statistics}

The rats were divided into 2 groups: study and control and each of these 2 into 5 further groups (1-5) according to the duration of the experiment. The duration was measured in days: $1^{\text {st }}$ group, 3 days; $2^{\text {nd }}$ group, 14 days; $3^{\text {rd }}$ group, 28 days; $4^{\text {th }}$ group, 42 days; $5^{\text {th }}$ group, 91 days. After completion of the experiment, the number of CART-immunoreactive (CART-IR) cells in the all layers of the urinary bladder wall was determined for each rat in the particular groups. The parameters were determined at two decimal places accuracy. The determined numbers of endocrine cells (in the individual layers of wall urinary bladder), as well as the duration of illness, were subjected to statistical analysis.

\section{Statistical analysis}

All the collected data were analyzed statistically using STATISTICA Version 10.0 (StatSoft Polska Inc., Kraszewskiego 36, 30-110 Kraków, Poland). The numbers of NE cells were analyzed using the Mann-Whitney test for independent variables. When testing statistical 
hypotheses, $\mathrm{P}<0.05$ was assumed as the level of significance.

\section{Results}

No significant differences between the two control groups of rats were observed in the obtained results of the study. Only the results concerning sham-operated animals were taken into account. Blood pressure monitoring showed that, at week 6 of the experiment the blood pressure in the renovascular hypertensive rats stabilized at $162.6 \pm 2.19 \mathrm{mmHg}$, while in control groups remained at $120.2 \pm 5.89$ $\mathrm{mmHg}$. Hypertensive rats were gaining weight at a similar rate as normotensive animals. Immunohistochemical (IHC) staining enabled the identification of CART-IR cells in the entire urinary bladder wall, both in the normotensive and hypertensive group during all the weeks of induced hypertension. Microscopic observations allowed the location of CART-positive cells, as well as their numbers in relation to the duration of the disorder. Analyzing the location of endocrine cells, in all experimental groups, the most numerous CART-IR cells were found in the urinary bladder muscularis layer and the submucosa (Figure 1A), whereas they were only a few observed in the transitional epithelium and occasionally under urothelium (Figure 1B).

The observed cells were predominantly individually scattered or formed small groups of 2-3 (Figure 1C), sporadically 5-6 cells (Figure 1D).

\section{Quantitative evaluation of CART-IR cells}

Statistical analysis confirmed the intuitional view that, in the first stage of the hypertension, the greatest changes included increased activity of NE cells with a significant increase in their mean number in the experimental group (Table 1). An increase of nearly $50 \%$ was observed three days after ligation of the left renal artery in the urinary bladder walls of the rats from the experimental group (Figure 2A), in comparison with their counterparts in the control group (Figure 2B).

In the next experimental group, i.e. the twoweek one, two weeks after the ligation procedure, a rise in the numbers of NE cells secreting CART was also observed in the control group, though lower when compared with the $1^{\text {st }}$ study group. In the $3^{\text {rd }}$ study group (28 days), endocrine cell density $(23.88 \pm 6.06)$ in the animals with renovascular hypertension only slightly differed from the $1^{\text {st }}$ study group. In the analysis, the greatest population of CART-IR cells (in normotensive and hypertensive rats) in the experimental model of unilateral renal artery stenosis was observed after 42
Table 1. Number of CART-immunoreactive cells in the urinary bladder of control and the $2 \mathrm{~K} 1 \mathrm{C}$ rats at different times of renovascular hypertension (mean $\pm \mathrm{SD}$ ).

\begin{tabular}{ccc} 
Tlime after artery clipping procedure & Group of rats & Number of CART-IR cells \\
\multirow{2}{*}{3 days } & Control & $13.67 \pm 2.12$ \\
& $2 \mathrm{~K} 1 \mathrm{C}$ & $23.63 \pm 4.38^{*}$ \\
\multirow{2}{*}{14 days } & Control & $14.67 \pm 4.24$ \\
& $2 \mathrm{~K} 1 \mathrm{C}$ & $22.38 \pm 4.06^{*}$ \\
\hline \multirow{2}{*}{28 days } & Control & $15.33 \pm 0.71$ \\
& $2 \mathrm{~K} 1 \mathrm{C}$ & $23.88 \pm 6.06^{*}$ \\
& Control & $18.00 \pm 1.41$ \\
& $2 \mathrm{~K} 1 \mathrm{C}$ & $25.50 \pm 5.68^{*}$ \\
\hline \multirow{2}{*}{91 days } & Control & $16.00 \pm 2.83$ \\
& $2 \mathrm{~K} 1 \mathrm{C}$ & $21.13 \pm 7.06^{*}$ \\
\hline
\end{tabular}

Cart-IR, CART-immunoreactive; 2K1C, Goldblatt's model of hypertension - two-kidney, one clip model; *P>0.05.
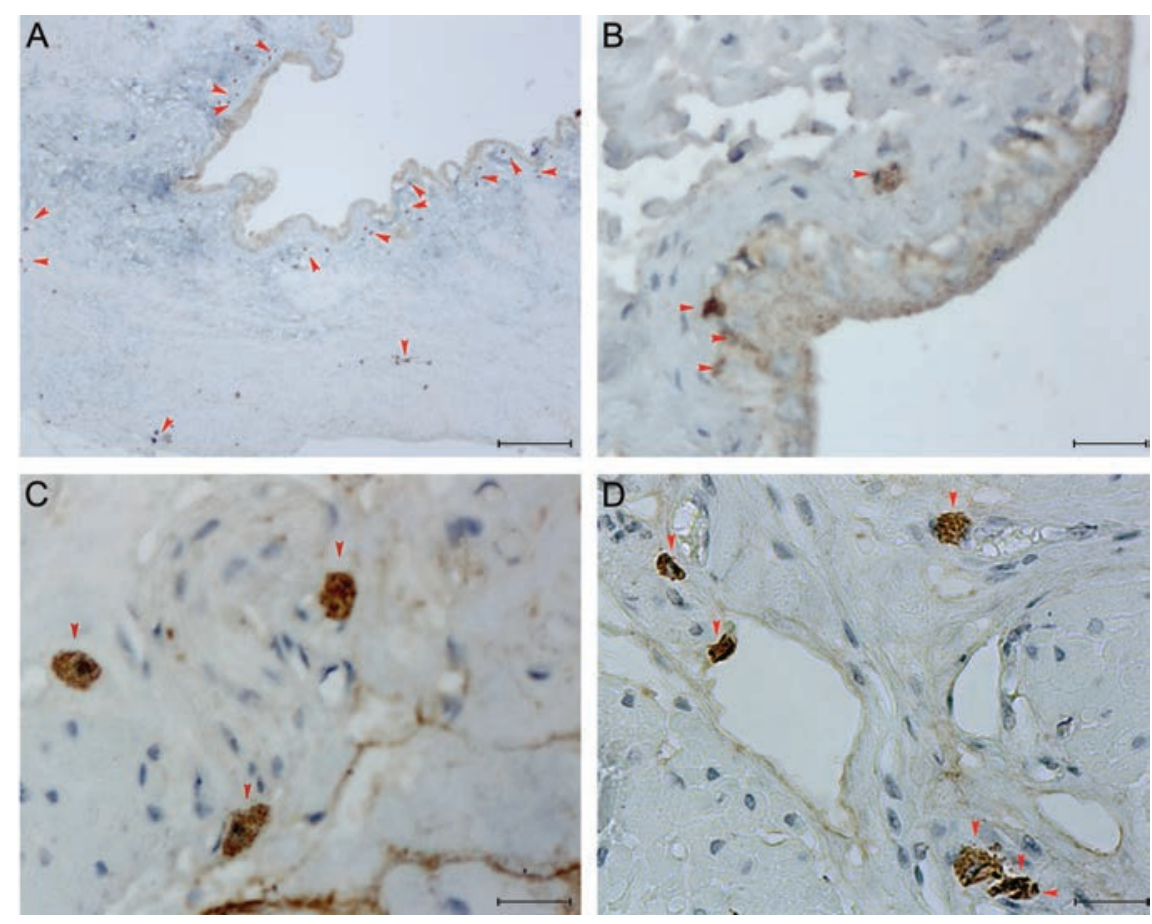

Figure 1. A) CART-IR cells in submucosa and membrane muscularis. B) CART-containing cells in the transitional epithelium and occasionally under urothelium. C) Small groups of 2-3 CART-IR cells in the muscularis layer. D) Group of 5-6 CART- IR cells in the muscularis layer. Scale bars: $20 \mu \mathrm{m}$.
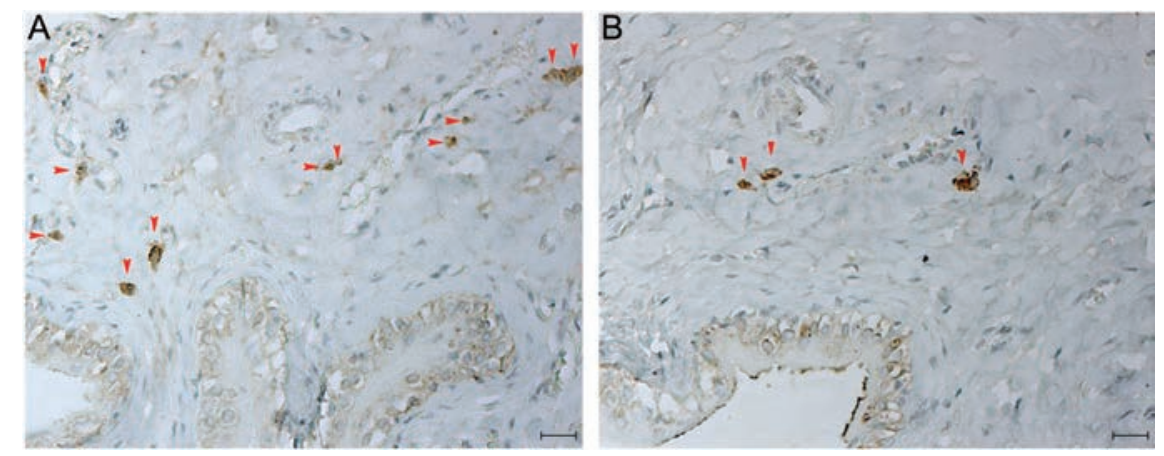

Figure 2. A) Three-day form artery clipping procedure; numerous CART-containing cells in the muscularis layer. B) Animals with 3-day, the control group; few NE cells in the muscularis layer. Scale bars: $20 \mu \mathrm{m}$. 
days of illness in comparison with the other groups included in the experiment. In this group, much larger clusters of cells were also noticed in comparison with the other study groups. The clusters consisted of up to 5-6 cells and were mainly located in the muscularis layer (Figure 3A). Numerous cells were also reported in the urothelium only in this study group. In the mucosa immunoreactive cells were observed in the surface cell layer of transitional epithelium (Figure 3B). At the same time, in the other groups (experimental and control) the cells with positive reaction to the anti-CART antibody in cytoplasm were most often individually scattered or clustered in small groups of 2-3 cells. After 13 weeks from the surgery, the population of CART-IR cells found in the urinary bladder of hypertensive rats significantly decreased in number when compared $(21.13 \pm 7.06)$ with the other groups.

\section{Discussion}

Renovascular hypertension caused by renal artery stenosis may lead to renal hypoperfusion and development of a sequence of changes in hormone and neuropeptide secretion, which in consequence leads to hemodynamic disorders. Multiple studies have proved that, in patients, renal artery stenosis in early stages of the illness is an incentive to increasing renin production by the ischemic kidney and, as a result, to increased activity of the HPA axis as well as excessive production of angiotensin II. ${ }^{2,19,22}$ Among other significant factors in the pathogenesis of hypertension there are active substances correlated with the HPA axis and the sympathetic nervous system. It is assumed that, besides the stimulation of the renal hormonal system, there is an inten- sified activity of DNES cells, which are diffusely distributed throughout the body and produce pressor substances. ${ }^{23}$ The group of substances with pressor characteristics, playing a vital role in pathophysiology of hypertension, includes those related to hunger, such as ghrelin, leptin or NPY.10,24

Another substance that has influence on hypertension, and still constitutes a subject of many discussions, is CART. It is principally known for its role in feeding but, as shown in a number of studies, its role is not limited only to hypophagia as it has an impact on many organs and systems.,,6,25 CART is a peptide involved in a number of physiological processes including modulation of the HPA axis and cardiovascular regulation. ${ }^{15,16,26-30}$ Its function as a factor in the development of hypertension, despite numerous studies, remains controversial. Arguments in favour of CART influence on the cardiovascular system are provided in studies of Hwang et al. ${ }^{31}$ and Matsumura et al ${ }^{10,15}$ In their experiments, after direct infusion of CART to cerebral ventricles, Matsumura et al. ${ }^{10}$ noted an increase in mean blood pressure and plasma glucose concentration. On the other hand, Iliff et al. ${ }^{29}$ reported that, in isolated cerebral arterioles, CART peptide (CARTp) acts directly to produce endothelium-dependent constriction via the endothelin signaling pathway.

Visualization of innervation changes, together with the development of nervous structures secreting CART in the urinary bladder of rats, was performed by Zvarova et al. ${ }^{7}$ However, the results did not concern normotensive animals. The knowledge relating to the identification and distribution of CART in pathological states caused by hypertension has so far been limited only to specific organs of the alimentary tract, ${ }^{4}$ as well as the bladder and ureters. ${ }^{6}$

Kasacka and Piotrowska ${ }^{4}$ postulated the connection of CART with hypertension and
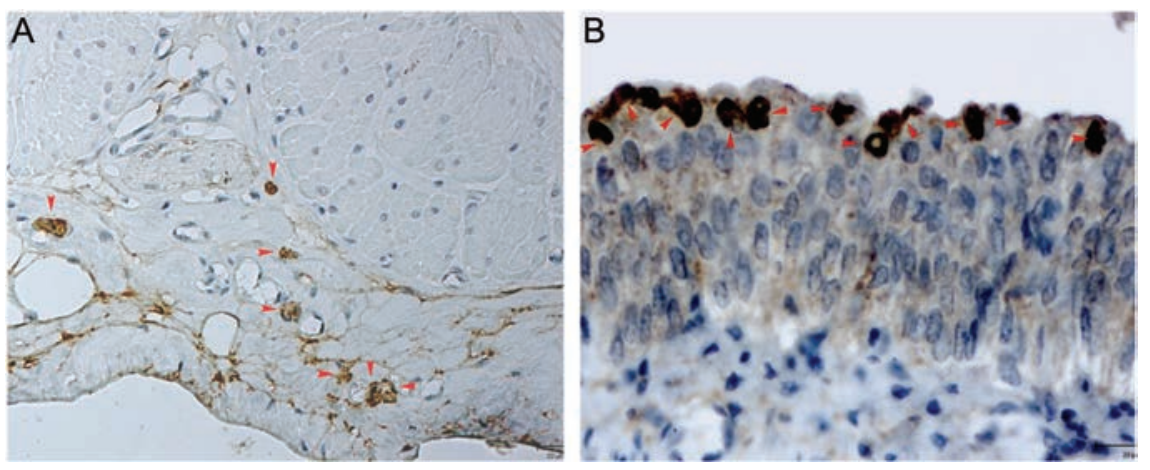

Figure 3. A) Forty-two-day experimental model of unilateral renal artery stenosis; visible immunohistochemical reaction in numerous CART-containing cells in muscularis layer. B) CART-containing cells observed in surface cell layer of the transitional epithelium. Scale bars: $20 \mu \mathrm{m}$.

used an IHC method in the gastrointestinal tract (GI tract) of rats in an experimental model of unilateral renal artery stenosis. After 42 days from inducing the condition, the researchers measured the number of NE cells and structures secreting CART in comparison with normotensive animals. The results of the observations were in accordance with the prognosis because the hypertension caused a significant increase in the mean number of CART-IR cells and structures. A close connection between hypertension and the scattered nervous system has also been proved in the region of the lower urinary tract in hypertensive rats. ${ }^{6}$ Besides the abovementioned studies, no information has been found on the subject of dynamics of changes in CART-IR cells in the urinary tract of hypertensive animals in relation to the duration of the illness. The connection between the duration of hypertension and the number of DNES cells has been documented only in studies of Kasacka and Arciszewska $^{3}$ who analyzed the dynamics of changes in the number of NE cells under the influence of 3-, 14-, 28-, 42-, and 91-day hypertension. The aim of their studies was to examine the distribution, morphology and dynamics of changes of calcitonin gene related peptidecontaining cells in the lungs of rats in the twokidney, one-clip (2K1C) renovascular hypertension model. The authors proved that there is a connection between hypertension, the number of NE cells containing CGRP and the duration of hypertension. Analyzing the results, the greatest intensity of NE cells in the lungs of rats was noticed 14 days after the surgical procedure. ${ }^{3}$

In this paper, the presented data concern the duration of hypertension and the number of CART secreting cells in the urinary bladder of rats in a renovascular hypertension model. After 3 days, the number of NE cells in the urinary bladder walls of the rats that underwent the surgical procedure of inducing renovascular hypertension significantly increased. This pattern was not described by Kasacka and Arciszewska $^{3}$ in rat lungs after 2K1C. Three and 28 days after clamping the left renal artery, the number of cells reached comparable levels in the control and study group. However, it was lower in the study group after 3 days since hypertension had been induced. In contrast, Kasacka and Arciszewska ${ }^{3}$ observed the greatest number of CGPR-IR cells 14 days after the procedure in the lungs of hypertensive rats. In our observations, the highest parameters were noted only 6 weeks after hypertension was induced. These and earlier promising data let us assume that the studied peptide may play an active role in the development of renovascular hypertension and related disorders. ${ }^{4,6}$ Renovascular hypertension caused by renal artery stenosis in original Goldblatt's experi- 
mental model (2K1C model of hypertension) led to chronic ischemia of the left kidney. Circulatory disorders leading to the disintegration of nervous and endocrine systems were probably conducive to changes in the diffuse neuroendocrine system, manifested in an increased activity of NE cells. The two-kidney one-clip (2K1C) Goldblatt model is an animal model widely used to study the pathophysiology of hypertension. The establishment and maintenance of hypertension principally depend on renin-angiotensin system (RAS) activity. ${ }^{32}$ Angiotensin II (Ang II), a key element of this system, plays a pivotal role in the pathogenesis of clinical and experimental hypertension, ${ }^{33}$ and also modulates fluid balance and the cardiovascular ${ }^{34}$ and urinary systems. As a vascular risk factor, hypertension has been reported to play a role in the development of urinary tract symptoms. ${ }^{35}$ In animal models, cystometric changes and bladder overactivity have also been reported in hypertensive rats. ${ }^{36}$ Renovascular hypertensive rats (2K1C) have also been found to develop bladder incontinence, frequency and nocturia. ${ }^{37}$ Patients with confirmed hypertension in clinical studies have been, in turn, found to develop bladder over reactivity and urinary incontinence. ${ }^{38-40}$ In the course of hypertension, the increase in CART-IR numbers in the urinary tract, the gastrointestinal tract ${ }^{4,6}$ and the respiratory system proves their important role in the homeostasis and dysfunction of the studied organs in chronic renal failure. Beside the academic aspect, the practical side of the research seems to be particularly valuable, indicating potential possibilities of using biologically active substances, synthesized by DNES cells in the therapy of hypertension symptoms, especially when hypertensions concerns multiple organs. ${ }^{4,6}$

In conclusion, CART seems to be a new important link in the pathogenesis of hypertension, inactivating the endocrine system. The final assessment of the role of the CART peptide in the pathogenesis of hypertension requires further studies, as its role in the lower urinary tract is still unknown. This study provided more questions than answers.

\section{References}

1. Kearney PM, Whelton M, Reynolds K, Muntner P, Whelton PK, He J. Global burden of hypertension: analysis of worldwide data. Lancet 2005;365;217-23.

2. Januszewicz W, Szczepa ska-Sadowska E, Januszewicz A, Prejbisz A. Neurogenic aspects of hypertension. Arterial Hypertens 2008;12:1-11.

3. Kasacka I, Arciszewska E. Dynamics of cal- citonin gene-related peptide-like cells changes in the lungs of two-kidney, oneclip rats. Eur J Histochem 2012;56:e10.

4. Kasacka I, Piotrowska Z. Evaluation of density and distribution of CARTimmunoreactive structures in gastrointestinal tract of hypertensive rats. Biofactors 2012;38:407-15.

5. Janiuk I, Młynek K, Wysocki J. Identification and location cocaine and amphetamine in bovine stomach. Acta Histochem 2013;115:371-5.

6. Janiuk I, Kasacka I. Distribution of cocaine and amphetamine regulated transcript in ureters and urinary bladder of hypertensive rats. J Biol Regul Homeost Agents 2013;27:409-16.

7. Zvarova K, Dunleavy JD, Vizzard MA. Changes in pituitary adenylate cyclase activating polypeptide expression in urinary bladder pathways after spinal cord injury. Exp Neurol 2005;192:46-59.

8. Kasacka I, Janiuk I, Lewandowska A, Bekisz A, Lebkowski W. Distribution pattern of CART-containing neurons and cells in the human pancreas. Acta Histochem 2012;114:695-9.

9. Iliff JJ, Alkayed NJ, Gloshani KJ, Traystman RJ, West GA. Cocaine- and amphetamine-regulated transcript (CART) peptide: a vasoactive role in the cerebral circulation. J Cereb Blood Flow Metab 2005;25:1376-85.

10. Matsumura K, Tsuchihashi T, Fujii K, Iida M. Neural regulation of blood pressure by leptin and the related peptides. Regul Pept. 2003;114:79-86.

11. Richardson RJ, Grkovic I, Anderson CR. Cocaine- and amphetamine-related transcript peptide and somatostatin in rat intracardiac ganglia. Cell Tissue Res 2005;324:17-24.

12. Elias CF, Lee C, Kelly J, Aschkenasi C, Ahima RS, Couceyro PR, et al. Leptin activates hypothalamic CART neurons projecting to the spinal cord. Neuron 1998;21: 1375-85.

13. Vasseur F, Guérardel A, Barat-Houari M, Cottel D, Amouyel P, Froguel P, et al. Impact of a CART promoter genetic variation on plasma lipid profile in a general population. Mol Genet Metab 2007;90:199-204.

14. Luo Y, Shen H, Liu HS, Yu SJ, Reiner DJ, Harvey BK, et al. CART peptide induces neuroregeneration in rats. J Cereb Blood Flow Metab 2013;33:300-10.

15. Matsumura K, Tsuchihashi T, Abe I. Central human cocaine- and amphetamine regulated transcript peptide 55-102 increases arterial pressure in conscious rabbits. Hypertension 2001;38:1096-100.

16. Scruggs P, Dun SL, Dun NJ. Cocaine- and amphetamine-regulated transcript peptide attenuates phenylephrine-induced bradycardia in anesthetized rats. Am J Physiol Regul Integr Comp Physiol 2003;285:1496-1503.

17. Skobowiat C, Dowdy JC, Sayre RM, Tuckey RC, Slominski A. Cutaneous hypothalamic-pituitary-adrenal axis homolog: regulation by ultraviolet radiation. Am J Physiol Endocrinol Metab. 2011;301:484-93.

18. Lacka K, Czyzyk A. Hormones and the cardiovascular system. Endokrynol Pol 2008;59: 420-32.

19. Goldblatt H, Lynch J, Hanzal RF, Summerville WW. Studies on experimental hypertension I: the production of persistant elevation of systolic blood pressure by means of renal ischemia. J Exp Med 1934;59:347-9.

20. Stewart PM, Whorwood CB, Valentino R, Burt D, Sheppard MC and Edwards CR. 11beta-hydroxysteroid dehydrogenase activity and gene expression in the hypertensive Bianchi-Milan rat. J Hypertens 1993; 11:349-54.

21. Herman GE, Elfont EA. The taming of immunohistochemistry: the new era of quality control. Biotech Histochem 1991; 66:94-9.

22. Zellert T. Renal artery stenosis. Curr Treat Options Cardiovasc Med 2007;9:90-9.

23. Andersson KE, Arner A. Urinary bladder contraction and relaxation: physiology and pathophysiology. Physiol Rev. 2004;84:935-86.

24. Mizia-Stec K, Olszanecka-Glinianowicz M, Zahorska-Markiewicz B, G sior Z. Ghrelin as a potential factor that reduces blood pressure during weight loss treatment. Med Hypotheses Res 2005;2:469-79.

25. Kasacka I, Piotrowska Z, Car H, Janiuk I, Lebkowski W. Cocaine- and amphetamineregulated transcript: identification and distribution in human gastrointestinal tract. J Biol Regul Homeost Agents 2012;26:419-28.

26. Koylu EO, Couceyro PR, Lambert PD, Ling NC, DeSouza EB, Kuhar MJ. Immunohistochemical localization of novel CART peptides in rat hypothalamus, pituitary and adrenal gland. J Neuroendocrinol 1997;9: 823-33.

27. Smith SM, Vaughan JM, Donaldson CJ, Rivier J, Li C, Chen A, Vale WW. Cocaineand amphetamine-regulated transcript activates the hypothalamic-pituitaryadrenal axis through a corticotropinreleasing factor receptor-dependent mechanism. Endocrinology 2004;145:5202-9.

28. Koylu E0, Balkan B, Kuhar MJ, Pogun S. Cocaine and amphetamine regulated transcript (CART) and the stress response. Peptides 2006;27:1956-69.

29. Iliff JJ, Alkayed NJ, Golshani KJ, Weinstein J, Traystman RJ, West GA. In vivo cerebrovascular effects of cocaine-and amphet- 
amine-regulated transcript (CART) peptide. J Cardiovasc Pharmacol 2008;52:82-9.

30. Ruginsk SG, Uchoa ET, Elias LL, AntunesRodrigues J, Llewellyn-Smith IJ. Hypothalamic cocaine- and amphetamine-regulated transcript and corticotrophin releasing factor neurons are stimulated by extracellular volume and osmotic changes. Neuroscience 2011;86:57-64.

31. Hwang LL, Chen CT, Li TL, Chiu CZ, Chi SF. Central pressor effects of CART peptides in anaesthetised rats. Neuropeptides 2004;38:69-76.

32. Ramos-Filho AC, Moscoso JA, Calmasini F, Faria Jde A, Anhê GF, Mónica FZ, Antunes E. Blockade of renin-angiotensin system prevents micturition dysfunction renovascular hypertensive rats. Eur J Pharmacol. 2014;738:285-92.

33. Ruzicka M, Leenen FHH. Experimental renovascular hypertension: methodological aspects and role of the reninangiotensin system, p. 49-87. In: D. Ganten, W. De Jong (eds.), Handbook of hypertension. Elsevier, 1994.

34. Robinson MM, McLennan GP, Thunhorst RL, Johnson AK. Interactions of the systemic and brain renin-angiotensin systems in the control of drinking and the centralmediation of pressor responses. Brain Res 1999;842:55-61.

35. Ponholzer A, Temml C, Wehrberger C, Marszalek M, Madersbacher S. The association between vascular risk factors and lower urinary tract symptoms in both sexes. Eur Urol 2006;50:581-6.

36. Jin LH, Andersson KE, Kwon YH, Park CS, Yoon SM, Lee T. Substantial detrusor overactivity in conscious spontaneously hypertensive rats with hyperactive behaviour.
Scand J Urol Nephrol 2009;43:3-7.

37. Yoshimura N, Kaiho Y, Miyazato M, Yunoki T, Tai C, Chancellor MB, Tyagi P. Therapeutic receptor targets for lower urinary tract dysfunction. Naunyn Schmiedebergs Arch Pharmacol 2008;377: 437-48.

38. Teleman PM, Lidfeldt J, Nerbrand C, Samsioe G, Mattiasson A, WHILA study group. Overactive bladder: prevalence, risk factors and relation to stress incontinence in middle-aged women. BJOG 2004;111: 600-4.

39. Steers WD. Pathophysiology of overactive bladder and urge urinary incontinence. Rev Urol 2002;4:7-18.

40. Boudokhane S, Marmouche H, Klii R, Jellad A, Mahjoub S, Ben Salah Frih Z. Urinary disorders and metabolic syndrome: prospective study. Prog Urol 2013; 23:256-61. 